\title{
LAS CONDICIONES CARCELARIAS EN EL PERÚ AFECTAN LOS DERECHOS FUNDAMENTALES. A PROPÓSITO DE LA COVID - 19
}

\author{
Juan Diego Castilla Zuñiga* \\ Universidad Católica Sedes Sapientiae \\ castillazunigaj@gmail.com
}

Resumen: El presente artículo de investigación desarrolla un tema de interés colectivo las condiciones carcelarias del Perú - cuya desatención como problema ha persistido por mucho tiempo. Sin embargo, cobra mayor relevancia por el contexto actual de la pandemia causada a raíz de la COVID-19. Dichas condiciones no cumplen con las mínimas medidas para un tratamiento adecuado, afectando diferentes derechos fundamentales, sobre todo en este contexto de emergencia sanitaria, afectando al derecho de la salud y vida.

La metodología utilizada es la inductiva, en aras de crear conocimientos que se basan en las evidencias presentadas, las mismas que se adquirieron de diferentes fuentes ya citadas, desarrollando el análisis. El presente trabajo se estructura en cinco apartados las cuales se inicia con la introducción, seguidamente del marco teórico y problema, además análisis, conclusiones y la bibliografía o referencias. Finalmente, es importante señalar la relevancia del tema a tratar para aportar ideas, concretas, reales y específicas a la sociedad y comunidad universitaria.

Palabras clave: Sistema penitenciario, condiciones carcelarias, COVID-19, derechos fundamentales, vulneración de derechos.

\section{PRISON CONDITIONS IN PERU AFFECTS FUNDAMENTAL RIGHTS WITH THE PURPOSE OF COVID - 19}

\begin{abstract}
This research article develops a topic of collective interest - the prison conditions of Peru - whose neglect as a problem has persisted for a long time. However, it is more relevant due to the current context of the pandemic caused by COVID- 19 . These conditions do not meet the minimum measures for adequate treatment, affecting

\footnotetext{
*Alumno del sexto ciclo de la Facultad de Derecho de la Universidad Católica Sedes Sapientiae (UCSS). Integrante de la Asociación Derecho y Realidad - Ius Et Re conformada por alumnos de la Facultad de Derecho UCSS. Integrante del Círculo de Estudios de Derecho Penal de la Facultad de Derecho UCSS.
} 
different fundamental rights, especially in this context of health emergency, affecting the right to health and life.

The methodology used is inductive, in order to create knowledge that is based on the evidence presented, the same that was acquired from different sources already cited, developing the analysis. The present work is structured in five sections which are the introduction, theoretical framework and problem, analysis, conclusions and the bibliography or references. Finally, it is important to point out the relevance of the topic to be discussed in order to contribute concrete, real and specific ideas to society and the university community.

Keywords: Prison system, prison conditions, COVID-19, fundamental rights, violation of rights.

\section{Introducción}

Para comenzar a estudiar y exponer la problemática planteada en el presente artículo es necesario manejar puntos, incluso conceptos que se tratarán o serán utilizados a lo largo del escrito, principalmente en lo referido al ámbito penitenciario del país.

Tratar el tema de las condiciones carcelarias, uno de los tantos problemas que desató la pandemia de la COVID-19, es saber también que cada interno se encuentra en las cárceles por diferentes delitos cometidos e incluso, simplemente, por supuestos delitos que aún no se han comprobado. Solo están dentro de estos recintos como medida de prevención.

La problemática planteada de las condiciones que afectan los derechos humanos comienza desde el trato que tiene el interno dentro de las cárceles, ya que se tiene un pensamiento equivoco, y en gran medida extremista, de que la persona por cumplir condena de cárcel tiene que morir en prisión, cuando verdaderamente no es así. Sin embargo, para conocer los tratamientos y condiciones de las prisiones en nuestro país, es necesario saber que los tratamientos se dan según regímenes penitenciarios para cada persona, además esta última se encuentra dentro de un sistema penitenciario.

El presente trabajo presenta un enfoque mixto, ya que desarrolla ideas de manera cualitativa, describiendo diferentes aspectos, así como ideas cuantitativas, basadas en estadísticas adquiridas de diferentes portales institucionales. Asimismo, el método inductivo empleado, ayudará a crear conocimientos a partir de todo lo expuesto 
anteriormente. El problema principal será ver cuán factible es mantener a un interno en las mismas condiciones carcelarias frente a una pandemia.

\section{El Sistema penitenciario}

Este concepto de sistema penitenciario ha sido confundido, en la mayoría de las veces, con el concepto de régimen, a tal punto que son tomados como sinónimos cuando realmente no lo son. De acuerdo con Solís Espinoza (2008), el sistema penitenciario vendría a ser:

La organización general que en materia penitenciaria se adopta en un país determinado, para la ejecución de las penas, organización general que sigue diversos criterios y dentro del cual quepan dos o más regímenes penitenciarios, porque es difícil que en una realidad nacional sea suficiente un solo régimen de ejecución penal para la multiplicidad de personalidades que caracterizan a los internos del país. (p. 7)

Conforme a lo expuesto en el párrafo anterior, el sistema penitenciario es la organización que se adopta, por parte del Gobierno, para ejecutar las penas que se les impone a las personas que cometieron delito. En el caso peruano, la institución encargada de administrar y dirigir el sistema penitenciario del país es el Instituto Nacional Penitenciario (INPE). Esta entidad, si bien es la encargada de manejar toda la organización, ha sido muy criticada durante los últimos años, ya que se ve directamente el desvío del objetivo que debe de tener como es preservar la integridad de los reos.

\section{Régimen penitenciario}

Otro término que se utiliza y está implicado en dicha problemática es el régimen. De acuerdo con Soliz Espinoza (2008), se tiene que entender por régimen:

... [al] conjunto de condiciones y medidas que se ejercen sobre un grupo de internos que presentan características similares. Asimismo, cada régimen cuenta también con una reglamentación o norma particular que lo diferencia de los otros. Por ello, el régimen de ejecución penal, que a veces erróneamente se denomina sistema penitenciario, viene a ser la especie dentro del género que es el sistema. (p. 7) 
En otras palabras, el régimen penitenciario es el conglomerado de todas las normas que van a dirigir la manera de como una persona pasará los días en la cárcel hasta cumplir su condena. No puede existir un solo régimen, ya que las cualidades de todos los internos no son las mismas. Hay personas, internos, que están entrado por vez primera a la cárcel, por lo que no ameritarán un mismo régimen como la persona delincuente que reincide.

\section{Tratamiento penitenciario}

Uno de conceptos que se va a mencionar en el presente artículo corresponde al tratamiento penitenciario. Empleando las palabras de Soliz Espinoza (2008) en torno al tratamiento, este viene a ser:

La acción o influencia dirigida a modificar la conducta delictiva del condenado, en función de sus peculiares características personales. Las influencias o medidas que se adopten, pueden ser de las más variadas dentro de cada régimen penitenciario... (p. 7)

Un tratamiento penitenciario va de acuerdo a cada régimen que se le aplica a la persona condenada. No obstante, en las páginas que siguen se evaluará con más detalle cada uno, o por lo menos algunos, de los aspectos que se incluyen en el tratamiento penitenciario.

\section{Condiciones carcelarias}

Para conocer la problemática central de la sobrepoblación de internos en las cárceles y hacer las cuestiones correspondientes, es necesario ver y analizar cuáles son las condiciones de las cárceles en el país. Desde los tratamientos, que incluirían los servicios y condiciones básicas, hasta la infraestructura en la que se encuentran.

Ha de recordarse que las condiciones carcelarias tienen que ver tanto con el tratamiento como con la infraestructura. De acuerdo con las reglas mínimas para el tratamiento de los reclusos adoptadas por el Primer Congreso de las Naciones Unidas sobre Prevención del Delito y Tratamiento del Delincuente (1955):

El tratamiento de los condenados a una pena o medida privativa de libertad debe tener por objeto, en tanto que la duración de la condena lo permita, inculcarles la voluntad de vivir conforme a la ley, mantenerse con el producto de su trabajo, y crear en ellos la aptitud para hacerlo. Dicho tratamiento estará 
encaminado a fomentar en ellos el respeto de sí mismos y desarrollar el sentido de responsabilidad.

Son claros los objetivos que se imparten en el mencionado congreso, sin embargo, habrá de verse cuáles son las condiciones de esos tratamientos en el Perú. En el país, mediante el Decreto Supremo N. 009-2007-JUS, se aprobó el reglamento de organización y funciones del instituto nacional penitenciario, en cual se establece los lineamientos para el tratamiento penitenciario. Empero, el área más importante es la Subdirección de Asistencia Penitenciaria, la misma que se encargará de plantear, organizar, ejecutar, priorizar las actividades y programas educativos, sociales, salud y religiosos para el tratamiento de las personas que se encuentran privadas de su libertad.

Cada persona que se encuentra en las cárceles tiene una capacidad y aptitud diferente que se puede sacar a flote para así ayudarlo en la resocialización de las personas. A continuación, se pasará a ver cuáles son las condiciones en las que se encuentran los internos privados de su libertad en las cárceles del Perú.

\subsection{Condiciones psicológicas de los internos}

De acuerdo con la Defensoría del Pueblo en su artículo:

La asistencia psicológica se encuentra regulada en el artículo $92^{\circ}$ del Código de Ejecución Penal y en los artículos $143^{\circ}$ al $146^{\circ}$ de su reglamento. En ellos se establece que la asistencia psicológica se brinda en aras de alcanzar los objetivos del tratamiento penitenciario.(p. 129)

Por medio de la asistencia psicológica se intenta ayudar a los internos, a través de terapias y diagnósticos, con el fin de tener una mejor vivencia y ayudar al proceso de resocializarlo a la comunidad. Es por ello que se tienen que regir bajos lineamientos de acciones que ayuden a la educación, convivencia con las personas y mejorar conductas sociales que rijan su vida. Además, se sabe que la asistencia psicológica también sirve para los menores de edad, cuyas madres perdieron su libertad y viven en el establecimiento hasta el término de su privación.

De acuerdo con las informaciones recogidas de la Defensoría del Pueblo (2018), la atención psicológica no es igual en todos los establecimientos penitenciarios, pues se realizan más terapias individuales y/o grupales. En algunos penales se dan de manera diaria y en otras no. A pesar de ello, existen dificultades para la aplicación de esta atención 
psicológica, que es parte de las condiciones que deben recibir los internos. Son dos las situaciones:

a) Se suspende la atención a las personas que se encuentran aisladas de los pabellones, ya sea por seguridad, por salud o castigo que se le impone.

b) La falta de personal de salud para atender a más de 90000 internos con los que cuenta las cárceles en este momento.

Existen 69 establecimientos penitenciarios en todo el Perú. No obstante, ya la población de internos alcanzó su límite y el personal de salud psicológica no se da abasto. En la Figura 1 podrá verse con más detalle la realidad de este hacinamiento:

Figura 1

Número de Penales con servicio de psicología

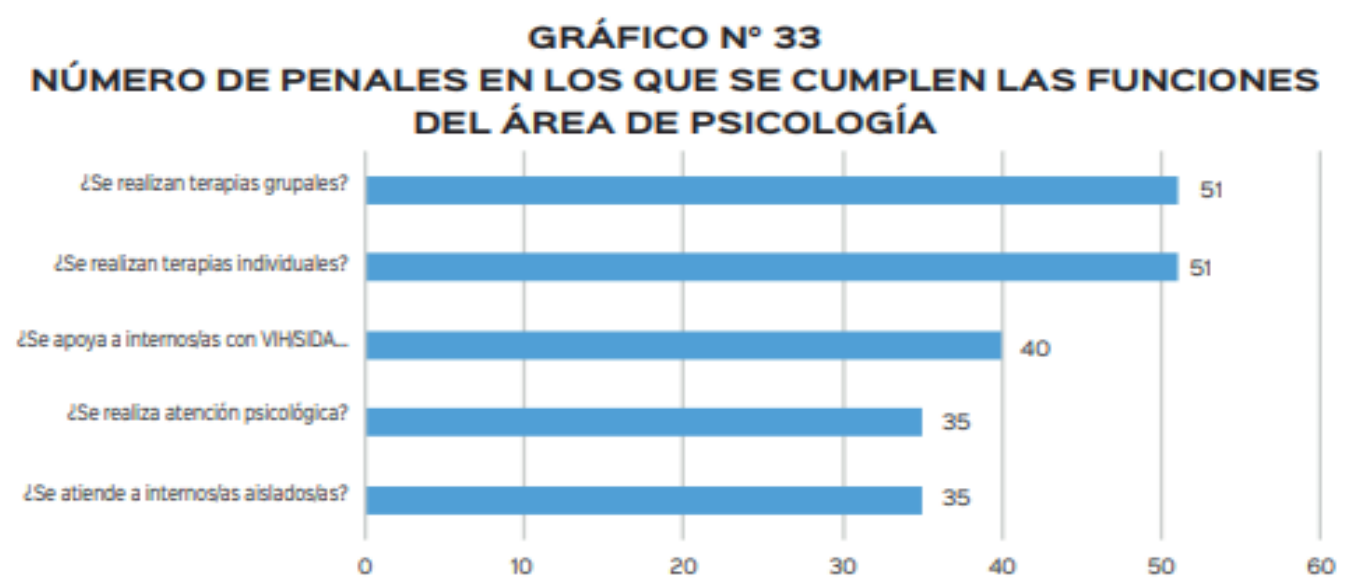

De "Retos del Sistema penitenciario peruano" (p. 130), por Defensoría del Pueblo, 2018.

Lo ideal es que, en unas buenas condiciones carcelarias, la atención psicológica sea una de los servicios primordiales, además que se ofrezcan en todos los establecimientos. Pero ahora la regularidad de estas atenciones solo se da cuando una persona lo solicite, debido a que existe como, ya se ha mencionado, una sobrepoblación carcelaria y menos personal de salud mental. Recordemos que un profesional de la salud, al igual que muchas profesiones, podría solo trabajar con grupos menores de 25 o 30 personas, sin embargo, debido a los problemas antes mencionados, esto no se puede cumplir en tales establecimientos.

Citando a la Defensoría del Pueblo (2019: 
A modo de ejemplo, cabe mencionar que en el penal de Iquitos de Varones, se ha advertido que para una población de 1056 internos solo se cuenta con un equipo multidisciplinario, que además realiza apoyo para la atención documentaria de la población del penal Mujeres de Iquitos una vez a la semana, ya que no se cuenta con personal de tratamiento. Así también, en el penal Cusco de Varones, solo se cuenta con dos asistentes sociales para un total de 2661 internos. (p.131)

En conclusión, la condición de atención psicológica no es la mejor, debido a los factores mencionados, entre uno de ellos, el hacinamiento, motivo de la problemática planteada.

\subsection{Condiciones Educativas de los internos}

La educación es un derecho que la Constitución Política de 1993 establece en sus artículos 13 y 17. En ella, se señala que la finalidad de la educación es el desarrollo integral de la persona, además, el Estado peruano debe de garantizarlo a través de una libre enseñanza. En el artículo 77, inciso 1 de las reglas mínimas para el tratamiento de los reclusos dada por la Organización de las Naciones Unidas se señala que se tomarán disposiciones para mejorar la instrucción de todos los reclusos capaces de aprovecharla, incluso la instrucción religiosa en los países en que esto sea posible. La instrucción de los analfabetos y la de los reclusos jóvenes será obligatoria y la administración deberá prestarle particular atención.

Se puede entender y deducir que los internos tienen que ser educados. De igual forma, tienen que contar con actividades que pongan distracción a la mente y los recree.

En las líneas del marco internacional, existen más normas dentro del código de ejecuciones penales que establecen las medidas que se deben adecuar y garantizar. Entre ellas, está la educación para una formación mínima requerida por las normas constitucionales, además de las internacionales. Como ya se indicó en párrafos anteriores, cada interno tiene capacidades, aptitudes y talentos diferentes que deben estar en desarrollo, a través de un mínimo de educación básica. Ha de reforzarse esas capacidades creando métodos de aprendizaje, los cuales desarrollen más actividades con valores académicos.

Después de haber concluido una parte del marco legal que tiene la educación penitenciaria, se pasará a ver la realidad de la aplicación de estas normas al sistema penitenciario del país. Para empezar, actualmente se cuenta con un total de 69 establecimientos penitenciarios a nivel nacional. Gracias a las estadísticas y comentarios recogidos por la Defensoría del pueblo (2018), es posible conocer un poco la realidad en 
cuanto a cuáles son las condiciones en el ámbito de educación. La institución mencionada señala los retos del sistema penitenciario peruano:

Del total de los 54 establecimientos penitenciarios supervisados, se identificó que 46 brindan estudios de educación Primaria, 39 de educación Secundaria y 36 de Alfabetización. Asimismo, 46 penales brindan actividades técnico productivas a través de los Centros de Educación Técnico Productivo-CETPRO, teniendo menor presencia las actividades de educación superior y técnico profesional. (2019, p. 113)

En una inspección, no a todos los establecimientos penitenciarios, sino solamente a 54, encontraron las deficiencias para brindar una educación necesaria y mínima para los internos. La Figura 2 servirá para ejemplificar mejor las observaciones hechas por la Defensoría:

Figura 2

Número de penales con actividades educativas

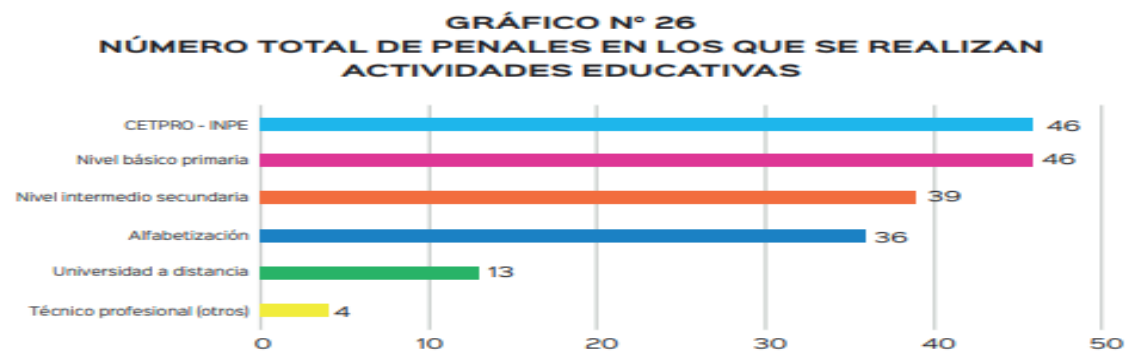

De "Retos del Sistema penitenciario peruano" (p. 112), por Defensoría del Pueblo, 2018.

El primer punto es preocupante, ya que, de la totalidad de los establecimientos penitenciarios, solo en 46 de ellos, existe un CETPRO y un nivel básico de primaria. En 39 un nivel intermedio de secundaria y de los demás puntos de educación, la situación llega a niveles paupérrimos.

A continuación, con ayuda de la Figura 3, se verá la cantidad de internos que reciben esta oportunidad de educación en los establecimientos que se encuentra disponible. 
Figura 3

Población penitenciaria en actividades educativas
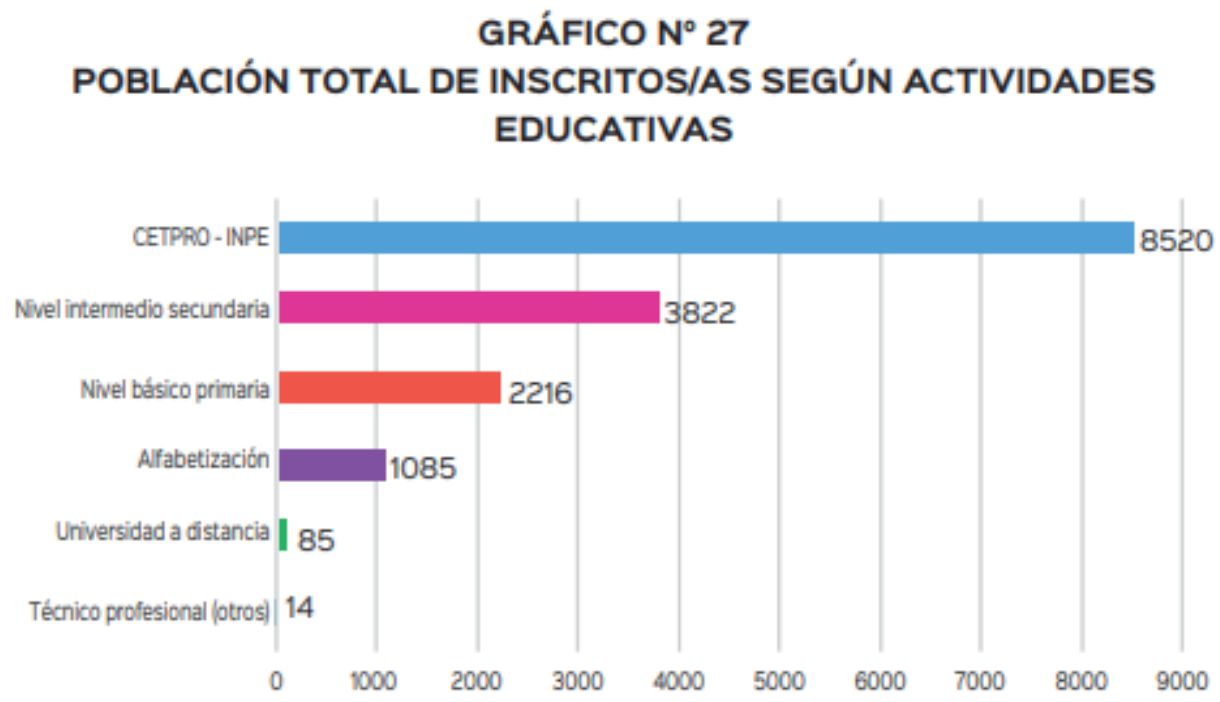

De "Retos del Sistema penitenciario peruano" (p. 113), por Defensoría del Pueblo, 2018.

De acuerdo con las estadísticas mostradas, menos del 15\% del total de la población penitenciaria accede a la educación mínima (primaria). Escasamente podría hablarse o mencionar las personas que acceden a la educación superior, ya que solo es menos del $1 \%$ del total.

Las dificultades, al igual que otras asistencias del sistema relacionadas con las condiciones que se le dan a los internos, son iguales:

a) La gran cantidad de personas privadas de su libertad

b) El poco personal que se cuenta para cubrir las necesidades de los internos.

c) La falta de infraestructura para acondicionamientos de centro de educación.

Es fundamental que el Estado promueva este derecho a la educación en los centros penitenciarios, que crezcan las oportunidades educativas y se llegue al objetivo en común.

\subsection{Condiciones laborales de los internos}

En lo referido a este tema, nuevamente puede acudirse a la Constitución Política del Perú, puesto que, en su artículo $2 .^{\circ}$, señala que el trabajo es un deber y un derecho. Del mismo modo, es la base del bienestar social, además de ser el medio para la realización de cada uno. 
En las normas internacionales se establece, entre las reglas mínimas para el tratamiento penitenciario, que la persona debe poner en manifiesto sus aptitudes y estar en contacto con el producto de su trabajo, no se debe de probar de ello.

Como se sabe, existen normas nacionales dentro del código de ejecución penal en donde queda precisada la importancia del trabajo de la persona interna para que contribuya al objetivo, que es la resocialización, además de poder aportar a los gastos que se le genera dentro como fuera del establecimiento. Pueden apoyar a su familia con el trabajo que realizan. Uno de los cuestionamientos que se realizan son las condiciones en los que los internos deberían de realizar esta actividad, ya que es deber del estado garantizar un espacio y condiciones dignas para ello.

Muchos de los de los penales en los que existe estos beneficios se caracterizan por tener una producción de objetos de madera o postres. Al respecto, la Figura 4 servirá para ejemplificar con más amplitud lo dicho anteriormente:

Figura 4

Número de penales con actividades laborales

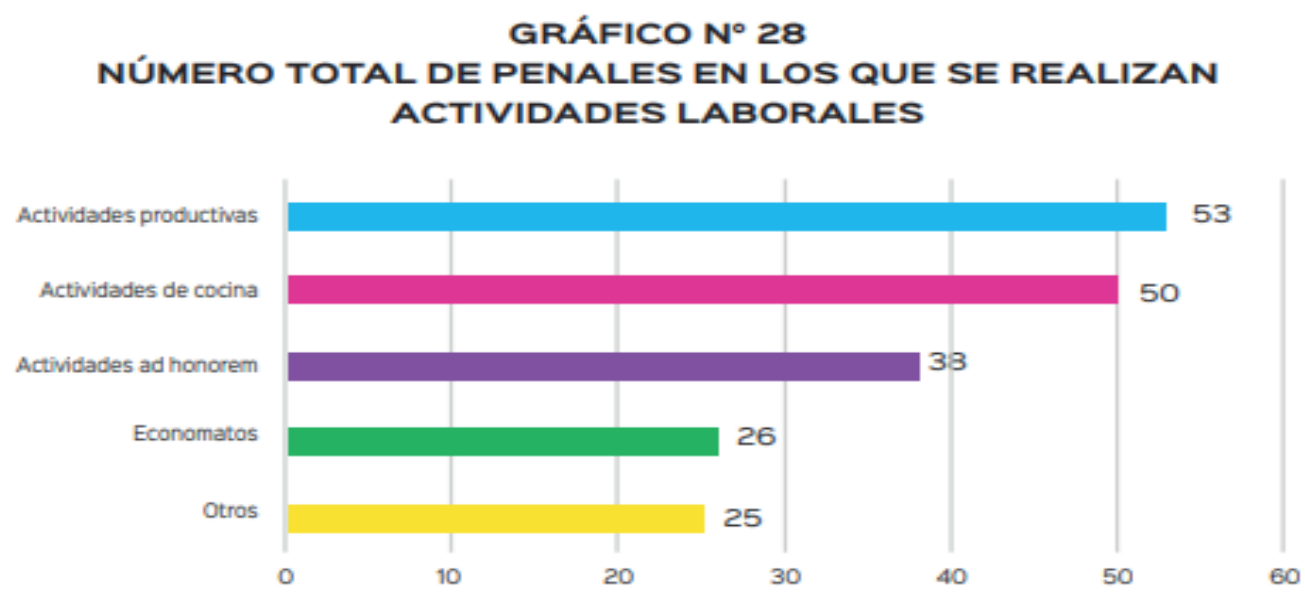

De "Retos del Sistema penitenciario peruano" (p. 116), por Defensoría del Pueblo, 2018.

En 53 penales se llevan a cabo estas actividades productivas. De acuerdo con el informe que emitió la Defensoría del Pueblo, no se llega a la totalidad de los establecimientos penitenciarios y eso es un gran problema, ya que no contribuye a su resocialización.

Para situarse en la cantidad de población penitenciaria, que son alrededor de 90000 internos, la Figura 5 ayudará a describir mejor la cantidad de personas inscritas según las áreas de trabajo: 
Figura 5

Número de internos inscritos en las actividades laborales

GRÁFICO N²9

POBLACIÓN TOTAL DE INSCRITOS/AS SEGÚN ACTIVIDADES

LABORALES

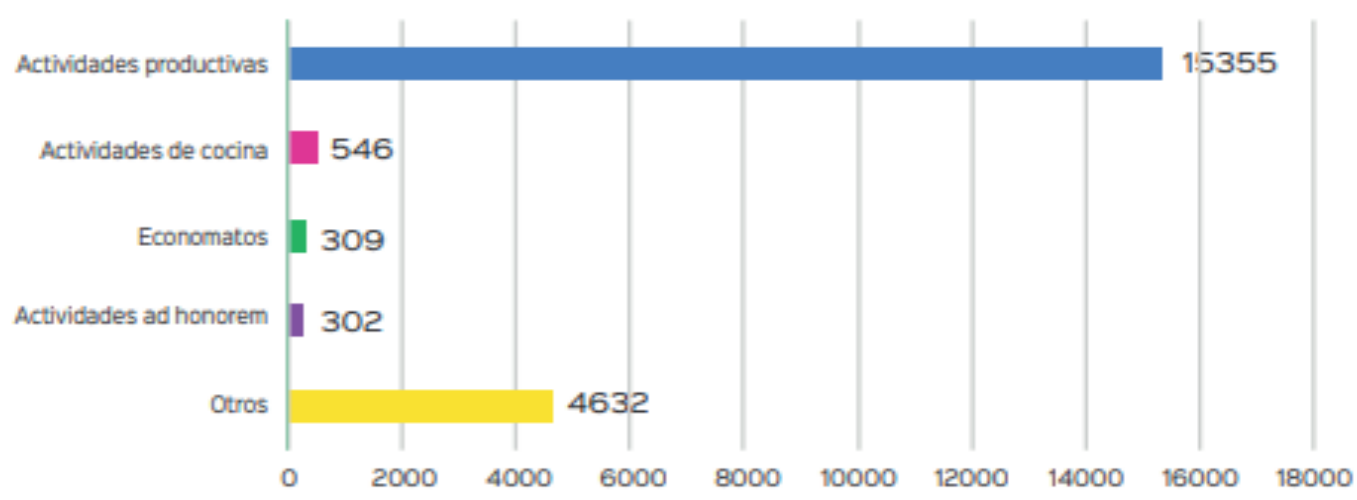

De "Retos del Sistema penitenciario peruano" (p. 117), por Defensoría del Pueblo, 2018.

Es una necesidad de la población que se encuentra privada de su libertad, generarse los ingresos económicos para así poder aportar a sus familias a los gastos o deudas que tengan en su vida. Sin embargo, se ve que las condiciones no son las mejores dentro de un sistema penitenciario que falta mejorar.

Para concluir este apartado, se debe mencionar que los datos recogidos son de hace dos años atrás, en un contexto al que se podría llamar "normal". Empero, nos vemos inmerso en una pandemia producida por un virus invisible, que ha sacado a flote las deficiencias de este sistema, además de un hacinamiento excesivo en las cárceles que no se puede mantener de esa manera.

\section{Condiciones de hacinamiento de los internos}

El Perú, al igual que muchos países del mundo, viene atravesando momentos difíciles debido a la pandemia de la COVID-19 (SARS-CoV-2), pandemia que no solo ha afectado a población de adultos mayores, sino a personas jóvenes y adolescentes. Este virus ha destapado diversos problemas que están relacionados principalmente con la salud, pero también con relación a un sistema penitenciario deficiente.

Uno de los retos que tiene el Gobierno, a propósito de la pandemia, es el de hacinamiento penitenciario. Existen 69 centros carcelarios en el Perú con más de 90000 internos privados de su libertad. 
El hacinamiento significa una sobrepoblación en las cárceles que pasan el límite permitido de capacidad. Si a ello le sumamos las condiciones en las que se encuentran, abordadas ya en párrafos anteriores, acaso ello no afecta sino los derechos humanos de las personas. Una persona privada de su libertad no deja de ser humano y no se le puede quitar los derechos fundamentales que son inherentes de ellos.

Es preciso recordar que el pasado 15 de marzo el Gobierno decretó el estado emergencia por los motivos ya señalados, mencionando y recomendando el aislamiento y distanciamiento social adecuado. Es en este momento donde cabe hacerse la preguntas: ¿Cuál es la situación de los reos en el país? ¿Se puede cumplir con las medidas sanitarias pertinentes? La respuesta sería que no, puesto que existe una sobrepoblación que se detallará ahora.

De acuerdo con el Instituto Nacional Penitenciario (2020):

La población del sistema penitenciario al mes de febrero 2,020 es de 129,115 personas. De ellos, 96,8702 se encuentran en establecimientos penitenciarios al tener mandato de detención judicial o pena privativa de libertad efectiva, mientras que 32,245 personas asisten a establecimientos de medio libre al haber sido sentenciados a penas limitativas de derechos, dictaminado medidas alternativas al internamiento, o liberados con beneficio penitenciario de semilibertad o liberación condicional. (p. 4)

En un año la población penitenciaria ha crecido excesivamente, llegando a más de los 96000 internos quienes se encuentran distribuidos en todos los establecimientos penitenciarios del país. Felizmente, existe otro porcentaje que tienen un beneficio penitenciario de semilibertad, porque de lo contrario la situación se haría más crítica.

\subsection{Evolución de la población penitenciaria}

Los internos de los penales del Perú han tenido un incremento excesivo en tan solo un año (de febrero 2019 a febrero de 2020). Gracias al último informe del INPE del el presente año, es posible precisar la evolución de los internos, tal como se aprecia en la Figura 6: 
Figura 6

Evolución población penitenciaria

\section{EVOLUCIÓN DE LA POBLACIÓN DEL SISTEMA PENITENCIARIO NACIONAL \\ FEBRERO 2,019 - FEBRERO 2,020}

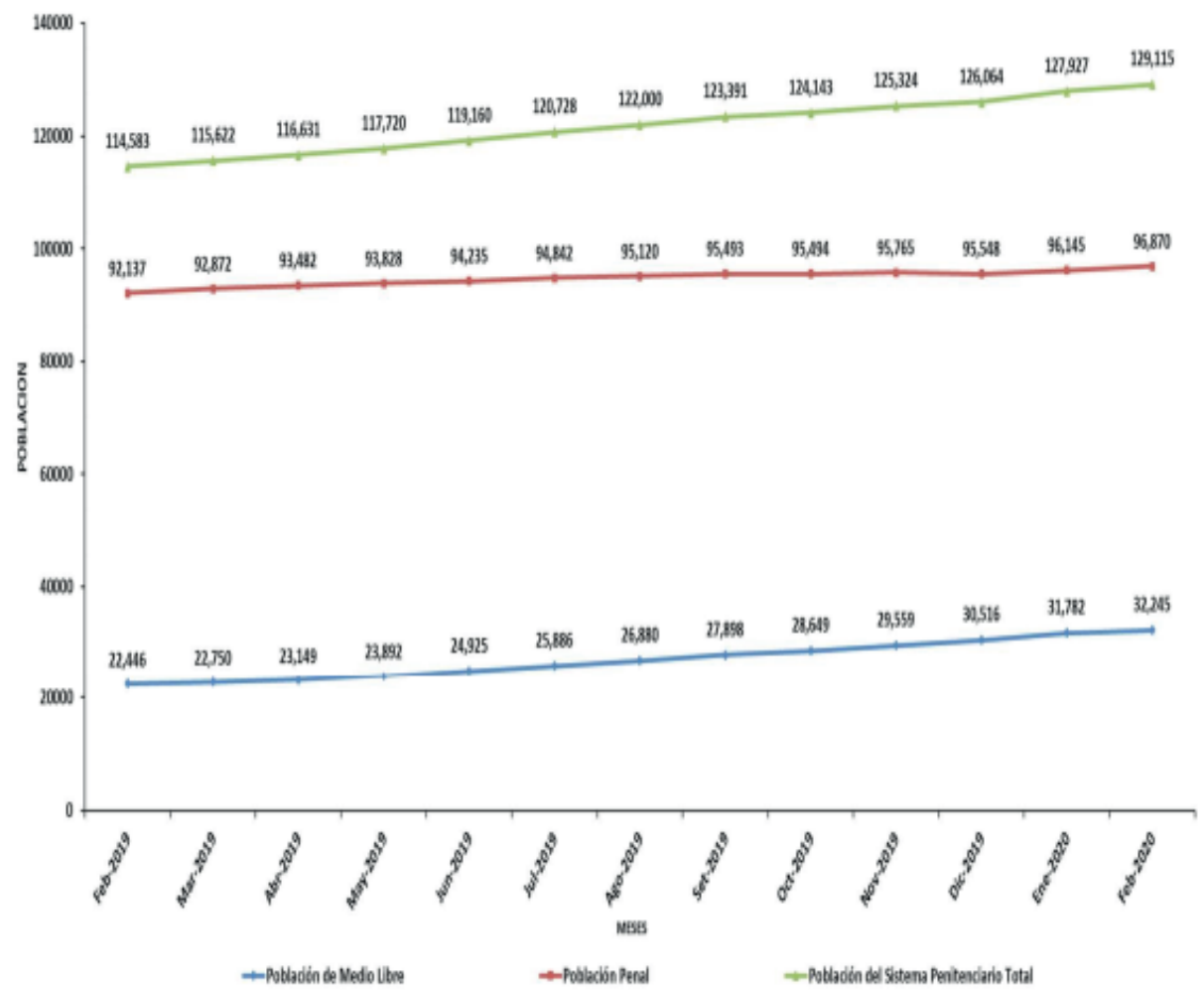

De “Informe estadístico" (p. 5), por INPE, 2020.

La población penitenciaria pasó de tener 114, 583 a tener 129, 115. Es decir, aumentó 14,532 en un solo año. Esta preocupante es cifra, ya que equivale a un aumento porcentual de 13 .

Si bien es cierto que en el total de la población carcelaria se considera tanto a las personas que se encuentran en establecimientos intramuros, privadas de libertad como en extramuros (personas liberadas con beneficio penitenciario), de todas maneras, el aumento de los que se encuentran en cárceles asciende a más de 96, 000 personas.

\subsection{Infraestructura penitenciaria}

E1 Perú cuenta con poca infraestructura carcelaria para albergar a la totalidad de los internos. Se menciona que el sistema penitenciario cuenta con dos tipos de establecimientos, 
los cuales son los Establecimientos penitenciarios intramuros y extramuros, como fue señalado en líneas anteriores.

En relación a los establecimientos penitenciario intramuros, donde se encuentran las personas privadas de libertad, el país cuenta con 69. Durante la pandemia se implementa uno más que era el antiguo penal San Jorge, para los internos activos.

Existen también los establecimientos extramuros que controla la población con beneficios penitenciarios. Sin embargo, se prestará atención a la infraestructura intramuros, que son los centros que albergan a los internos privados de su libertad. El informe del INPE (2020) destaca:

Respecto de la infraestructura intramuros. El Reglamento de Organización y Funciones del Instituto Nacional Penitenciario (ROF)3 señala en sus artículos $65^{\circ}$ y $66^{\circ}$ la clasificación de los penales en los tipos A, B, C y D. Así tenemos que hay un $37 \%$ de penales con más de 1,200 internos, que pueden ser denominados "establecimientos penitenciarios grandes". Sin embargo, al contrastarlos con su capacidad de albergue podremos afirmar que en realidad no son grandes en capacidad sino en ocupación lo que significa que se encuentran con mayor índice de sobrepoblación. (p. 10)

Los establecimientos de tipo D albergan de 1 a 199 personas; el de tipo C, de 200 a 899; el de tipo B, de 900 a 1199 y el de tipo A más de 1200 internos. Solo un poco más del $10 \%$ son considerados establecimientos grandes. No obstante, ya no es suficiente tener grandes, la realidad exige la necesidad de tener establecimientos "enormes" para albergar a la totalidad de internos en condiciones mínimas adecuadas.

\section{Capacidad de albergue, sobrepoblación y hacinamiento}

La capacidad de albergue hace referencia a las cantidades mínimas y máximas que debe o tiene un establecimiento penitenciario. Es claro que el hacinamiento surgirá cuando la cantidad de internos sobrepase el aforo permitido. Es importante resaltar que cuando el máximo de población excede el $20 \%$ de la capacidad total del establecimiento, se considera una sobrepoblación crítica.

Es muy cierto que el Perú figura entre los países que cuenta con una sobrepoblación excesiva en las cárceles, lo cual no permite que se brinde las condiciones necesarias para el objetivo en común que es la resocialización. A través de la Tabla 1 se podrá observar los niveles de hacinamiento en las cárceles peruanas: 
Tabla 1

Niveles de hacinamiento en la población carcelaria peruana

\begin{tabular}{|c|c|c|c|c|c|c|}
\hline $\begin{array}{l}\text { Oficinas Regio- } \\
\text { nales / } \\
\text { Establecimiento } \\
\text { Penitenciario }\end{array}$ & $\begin{array}{l}\text { Capacidad } \\
\text { de Alber- } \\
\text { gue } \\
\text { (C) }\end{array}$ & $\begin{array}{l}\text { P o b l a - } \\
\text { ción } \\
\text { Penal } \\
\text { (P) }\end{array}$ & $\begin{array}{l}\% \\
\text { O c u - } \\
\text { pación }\end{array}$ & $\begin{array}{l}\text { Sobre } \\
\text { Población } \\
\text { (S=P-C) }\end{array}$ & $\begin{array}{l}\text { \% Sobre } \\
\text { Población } \\
(\% \mathrm{~S})\end{array}$ & $\begin{array}{l}\text { H a c i n a - } \\
\text { miento } \\
(\% \mathrm{~S}>\mathbf{2 0} \%)\end{array}$ \\
\hline Total & 40137 & 97493 & $243 \%$ & 57356 & $143 \%$ & SI \\
\hline Norte-Chiclayo & 6514 & 18171 & $279 \%$ & 11657 & $179 \%$ & SI \\
\hline Lima - Lima & 17341 & 46018 & $265 \%$ & 28677 & $165 \%$ & SI \\
\hline Sur - Arequipa & 1252 & 4383 & $350 \%$ & 3131 & $250 \%$ & SI \\
\hline $\begin{array}{l}\text { Centro - Huan- } \\
\text { cayo }\end{array}$ & 2064 & 7313 & $354 \%$ & 5249 & $254 \%$ & SI \\
\hline $\begin{array}{l}\text { Oriente - Huán- } \\
\text { uco }\end{array}$ & 3240 & 6889 & $213 \%$ & 3649 & $113 \%$ & SI \\
\hline $\begin{array}{l}\text { Sur Oriente - } \\
\text { Cusco }\end{array}$ & 2918 & 6004 & $206 \%$ & 3086 & $106 \%$ & SI \\
\hline $\begin{array}{l}\text { Nor Oriente - } \\
\text { San Martin }\end{array}$ & 5352 & 6070 & $113 \%$ & 718 & $13 \%$ & SI \\
\hline $\begin{array}{l}\text { Altiplano - } \\
\text { Puno }\end{array}$ & 1456 & 2645 & $182 \%$ & 1189 & $82 \%$ & SI \\
\hline
\end{tabular}

Nota. De "Modulo de estadísticas" (p. 1), por Instituto Nacional Penitenciario, 2020.

Como se constata en las estadísticas, actualizadas hasta hace pocas horas antes de realizar este artículo, todas las áreas regionales penitenciarias que están distribuidas en ocho oficinas regionales se encuentran hacinadas.

Mención aparte tendrán los dos establecimientos que se encuentran con más hacinamiento y menos hacinamiento, tal como se muestra en la Tabla 2. 
Tabla 2

Establecimientos con mayor y menor hacinamiento - Oficina Regional Penitenciaria de Huancayo

\begin{tabular}{|c|c|c|c|c|c|c|}
\hline $\begin{array}{l}\text { Oficina Regional } \\
\text { Centro - Huan- } \\
\text { cayo }\end{array}$ & $\begin{array}{l}\text { Capaci- } \\
\text { dad de } \\
\text { albergue } \\
\text { (C) }\end{array}$ & $\begin{array}{l}\text { P o b l a - } \\
\text { ción Pe- } \\
\text { nal }\end{array}$ & $\begin{array}{l}\text { \% Ocu- } \\
\text { pación }\end{array}$ & $\begin{array}{l}\text { Sobre Po- } \\
\text { blación } \\
(\mathrm{S}=\mathrm{P}-\mathrm{C})\end{array}$ & $\begin{array}{l}\text { \% Sobre } \\
\text { Población } \\
(\% S)\end{array}$ & $\begin{array}{l}\text { H a c i n a - } \\
\text { miento } \\
(\% \mathrm{~S}>\mathbf{2 0} \%)\end{array}$ \\
\hline E.P. Huancayo & 680 & 2293 & $337 \%$ & 1613 & $237 \%$ & SI \\
\hline $\begin{array}{l}\text { E.P. Mujeres de } \\
\text { Concepción }\end{array}$ & 105 & 35 & $33 \%$ & -70 & $-66 \%$ & NO \\
\hline $\begin{array}{l}\text { E.P. de Chancha- } \\
\text { mayo }\end{array}$ & 120 & 778 & $648 \%$ & 658 & $548 \%$ & SI \\
\hline E.P. de Jauja & 85 & 132 & $155 \%$ & 47 & $55 \%$ & SI \\
\hline E.P. de Tarma & 48 & 138 & $287 \%$ & 90 & $187 \%$ & SI \\
\hline
\end{tabular}

Nota. De "Módulo de estadísticas” (p. 1), por Instituto Nacional Penitenciario, 2020.

Dentro del área de la Oficina Regional Penitenciaria de Huancayo, se encuentra la cárcel con el hacinamiento más crítico del país. A pesar de tener una capacidad de aforo de 120 personas, en la actualidad cuenta con 778 internos y eso equivale a una sobrepoblación de $548 \%$.

No es posible continuar con una condición así. Como se ha visto a lo largo del texto, no existen condiciones necesarias para mantener a más internos, mucho menos en un tiempo de emergencia sanitaria, en el cual el Estado debería de garantizar la salud de todos los seres humanos del país, sin discriminación alguna, por más que en el imaginario de muchos, los internos deberían morir en la cárcel, sin ver el lado humano de ello.

Es importante señalar que se ha buscado contrastar las cifras con estadísticas actualizadas, ya que no podría ser un artículo únicamente cualitativo, cuando realmente la realidad del hacinamiento se muestra en cifras por demás muy lamentables. 


\section{Derechos humanos: marco normativo}

Los derechos humanos son derechos intrínsecos de las personas tan solo por el hecho de pertenecer al género humano. Además, ciertos derechos son indispensables para la existencia de la vida y el desarrollo de su realización personal. Se le reconoce estos derechos a la persona como parte de la dignidad humana. Por tanto, al ser derechos intrínsecos, no podrán ser eliminados por un poder externo o arbitrario que lo imponga. No se le puede suspender, así la persona haya cometido un delito.

Los mencionados derechos han sido vulnerados a lo largo de la historia. Empero, los organismos internacionales pactaron firmar la Carta de las Naciones Unidas con el fin de positivizar los derechos fundamentales para garantizar y sancionar cuando sea necesario.

La Oficina del Alto Comisionado de las Naciones Unidas para los Derechos Humanos (2004) menciona:

La firma de la Carta de las Naciones Unidas en junio de 1945 situó los derechos humanos en la esfera del derecho internacional. Todos los Estados Miembros de las Naciones Unidas acordaron adoptar medidas para proteger los derechos humanos. Tres años más tarde, la adopción de la Declaración Universal de Derechos Humanos proporcionó al mundo «un ideal común para todos los pueblos y naciones», basado en el «reconocimiento de la dignidad intrínseca de los derechos iguales e inalienables de todos los miembros de la familia humana». (p. 4)

En 1945 comienza la formalización y reconocimiento de los derechos fundamentales por parte de todos los países. Tal como se menciona, se debería crear "un mundo ideal" para todos, el respeto hacia este debería prevalecer incluso al estar privado de la libertad.

Ha sido muy discutido los tratos que reciben los internos sentenciados por la comisión de un delito o incluso personas privadas de libertad con prisiones preventivas. En esta línea, los agentes penitenciarios acogen a los internos y desde ese momento se activa un sistema de trabajos y tareas que deben de cumplir para la seguridad, tratamiento y acogida de los privados de libertad. Los agentes son los primeros que deberán de respetar los derechos humanos en un establecimiento penitenciario, pero en la práctica, muchas veces, no se realiza.

Existen los marcos normativos para una buena administración, desde los internacionales que rigen todo el sistema penitenciario, ya que los estados se deben 
alinear a ellos. Al respecto, la Oficina del Alto Comisionado de las Naciones Unidas para los Derechos Humanos (1997) menciona:

En este marco, los instrumentos de derechos humanos, desde la Declaración Universal de Derechos Humanos hasta textos específicos como las Reglas mínimas para el tratamiento de los reclusos, el Conjunto de Principios para la protección de todas las personas sometidas a cualquier forma de detención o prisión o la Convención contra la Tortura y Otros Tratos o Penas Crueles, Inhumanos o Degradantes, ofrecen un conjunto de normas para ayudar al personal penitenciario a cumplir sus funciones mediante políticas y prácticas que sean legítimas, humanas y disciplinadas. (p. 5)

Como se menciona en la cita, existen marcos normativos internacionales que ayudan a prevenir la tortura y la vulneración de los derechos fundamentales que, como ya se ha dicho, no se puede quitar por el poder de uno. Todos los seres humanos como tales merecen condiciones dignas. Contrariamente, en el hacinamiento ello no se puede cumplir

A lo largo de los años, los países han firmado tratados internacionales que ellos mismos han ratificado en sus normas nacionales o en sus constituciones políticas. Uno de ellos es el Pacto Internacional de Derechos Económicos, Sociales y Culturales que se realizo el 19 de diciembre de 1966. En el mencionado tratado se protege principalmente el derecho al trabajo, el derecho a un adecuado nivel de vida, y el derecho a la educación.

También puede mencionarse la Convención contra la Tortura y Otros Tratos o Penas Crueles, Inhumanos o Degradantes; que se da el 10 de diciembre de 1984. Una convención muy importante para efecto de este trabajo y donde se constata que el hacinamiento va en contra de los derechos humanos. Esta convención da protección a las personas, los internos, contra la tortura y los malos tratos o tratos crueles que reciben.

Es por demás obvio que el Perú, teniendo más de 96, 000 personas recluidas cuando su capacidad solo es 50, 000 personas, contraviene esta convención internacional

Asimismo, la norma que cuenta con más alta jerarquía es la Declaración Universal de los Derechos Humanos y de las cuales se desprenden las dos anteriores. Como se sabe, esta declaración se dio el 10 de diciembre de 1948. Se optó por dejar esta norma para el final del texto, debido a que es la columna vertebral para poder entender de qué se habla cuando se habla del hacinamiento y por qué la situación actual tratada contraviene estos derechos. A continuación, se mencionarán algunos artículos de esta declaración. 
En el artículo 5 dice: "Nadie será sometido a torturas ni a penas o tratos crueles, inhumanos o degradantes".

En el artículo 23 se menciona: "Toda persona tiene derecho al trabajo, a la libre elección de su trabajo, a condiciones equitativas y satisfactorias de trabajo y a la protección contra el desempleo".

En el artículo 25 se afirma: "Toda persona tiene derecho a un nivel de vida adecuado que le asegure, así como a su familia, la salud y el bienestar...”.

Por último, el artículo 26 establece: “Toda persona tiene derecho a la educación”.

Solo citamos los artículos más relevantes para efecto de este trabajo. El hacinamiento, como se pudo ver a lo largo del artículo, no permite la satisfacción suficiente de profesionales que garanticen el desarrollo y la no vulneración de los derechos humanos como el derecho a la educación, al trabajo, a una vida digna.

Cabe añadir que en este pequeño apartado se ha tratado de demostrar y desarrollar solo unas pocas normas internacionales que el Estado debería de garantizar para todos los seres humanos, así ellos estén condenados por un delito. Dormir en una celda donde hay nueve internos, jamás podrá significar una calidad de vida adecuada.

\section{Conclusiones}

a. El Estado de adoptar medidas urgentes para deshacinar los establecimientos y no se ponga en riesgo la vida. Los organismos internacionales ya han dado consejos para que se llegue al objetivo y no se permita la vulneración de derechos de la población carcelaria. Además, cabe resaltar que no todos los mencionados reos cuentan con una sentencia fija, pues según el director del INPE, el 36\% de internos no cuenta con sentencia firme.

b. Un interno vive una penosa realidad, la afecta no solo su libertad, sino sobre todo sus derechos, entre ellos a la vida, a la dignidad o a la intimidad.

c. El objetivo de las penas es la resocialización, no se trata de soportar condiciones paupérrimas por parte de los internos hasta llegar a la muerte.

d. El hacinamiento es un atentado a la vida e integridad física, un hecho lamentable en el que el Estado debe intervenir. 


\section{Referencias}

Comisión Episcopal de Acción Social. Programa Justicia Penal y Penitenciaria. (2006). Informe Penitenciario. Una mirada al mundo carcelario peruano. Editorial Roel. https://www.corteidh.or.cr/tablas/23775.pdf

Defensoría del Pueblo. (2019). Retos del Sistema Penitenciario Peruano: Un diagnóstico de la realidad carcelaria de mujeres y varones. https://www.defensoria.gob. pe/wp-content/uploads/2019/04/Retos-del-sistema-penitenciario.pdf.

Decreto Supremo N. 009-2007-JUS. (2007). Ministerio de Justicia y Derechos humanos. https://www.peru.gob.pe/docs/PLANES/15328/PLAN_15328_2015_ROF. PDF

Instituto Nacional Penitenciario. (2020). Informe estadístico del Instituto Nacional Penitenciario. https://www.inpe.gob.pe/normatividad/documentos/4369informe-estadistico-febrero-2020/file.html

Módulo de estadísticas del Instituto Nacional Penitenciario. (2020). Instituto Nacional Penitenciario https://www.inpe.gob.pe/estad\%C3\%ADstica1.html

Oficina del Alto Comisionado de las Naciones Unidas para los Derechos Humanos. (1966). Pacto Internacional de Derechos Económicos, Sociales y Culturales https://www.ohchr.org/sp/professionalinterest/pages/cescr.aspx

Oficina del Alto Comisionado de las Naciones Unidas para los Derechos Humanos. (1984). Convención contra la Tortura y Otros Tratos o Penas Crueles, Inhumanos o Degradantes. https://www.ohchr.org/sp/professionalinterest/pages/cat.aspx

Oficina del Alto Comisionado de las Naciones Unidas para los Derechos Humanos. (1977). Reglas mínimas para el tratamiento de los reclusos. Primer Congreso de las Naciones Unidas sobre Prevención del Delito y Tratamiento del Delincuente. https://www.ohchr.org/sp/professionalinterest/pages/treatmentofprisoners. $\operatorname{aspx}$

Organización de las Naciones Unidas. (1948). Declaración Universal de Derechos Humanos. https://www.un.org/es/universal-declaration-human-rights/

Solís, A. (2008). Política Penal y Política Penitenciaria. Cuaderno N. 8. Departamento Académico de Derecho Pontificia Universidad Católica del Perú. https:// departamento.pucp.edu.pe/derecho/wp-content/uploads/2019/05/politicapenal.pdf

Tapullima, G. (20 de febrero de 2020). César Cárdenas, presidente del Instituto Nacional Penitenciario del Perú (INPE): “Cerca del 48\% de presos no cuentan con 
sentencias". Ojo público. https:/ojo-publico.com/1622/dato-de-presidentedel-inpe-sobre-presos-sin-sentencia-es-enganoso

Vega, F. (1972). Regímenes penitenciarios. Derecho PUCP, (30), 197-204. DOI: https:// doi.org/10.18800/derechopucp.197201.014 
